
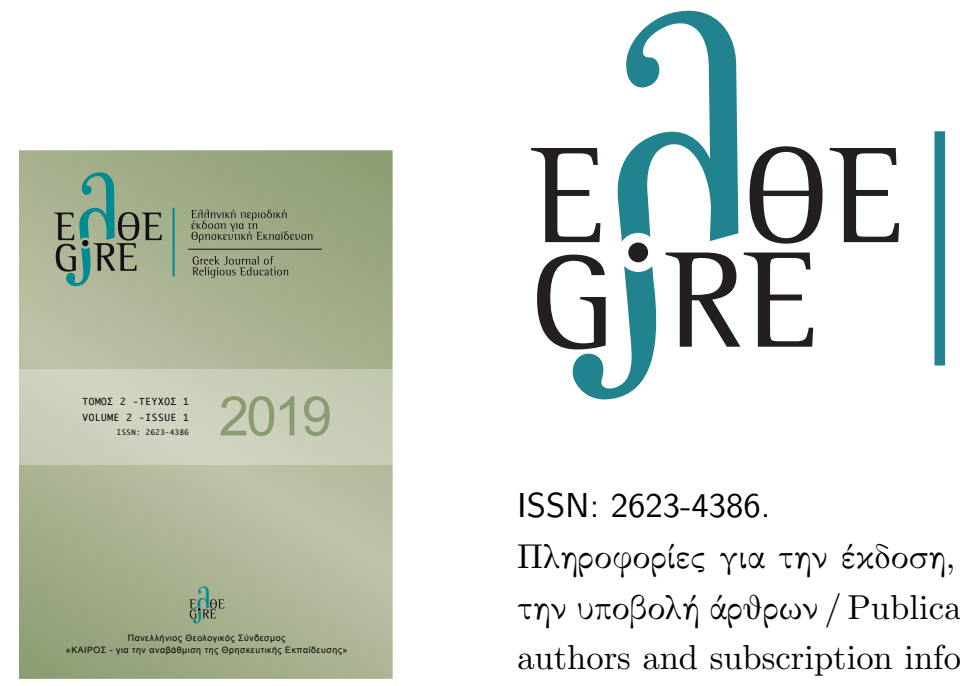

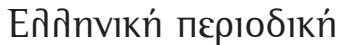

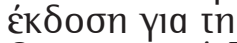

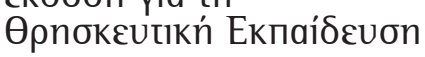

Greek Journal of

Religious Education

ISSN: 2623-4386.

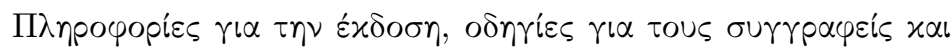

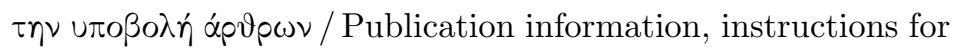
authors and subscription information: http://www.gjre.gr

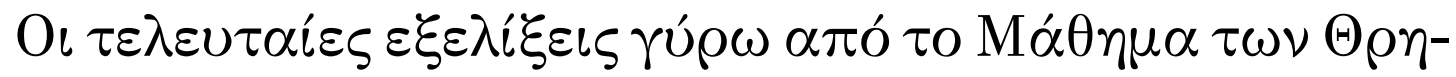

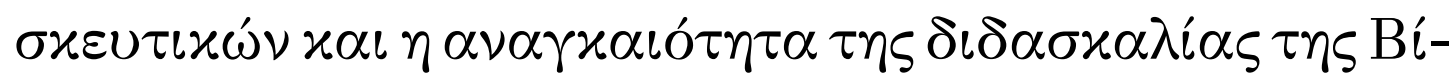

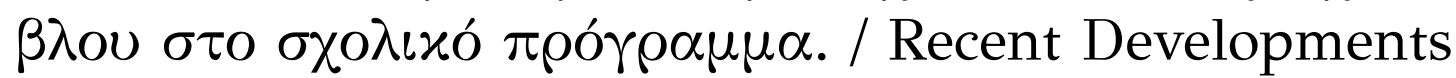 concerning Religious Education and the Necessity of Teaching the Bible in the School Curriculum.
}

X

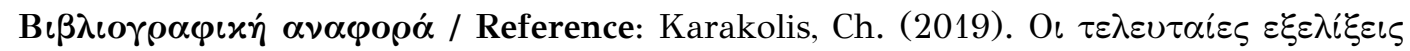

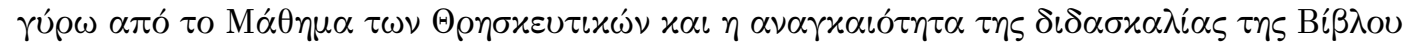

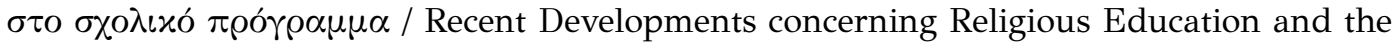

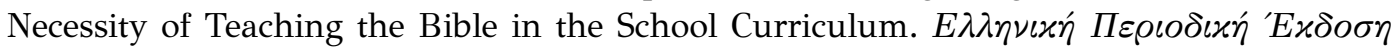

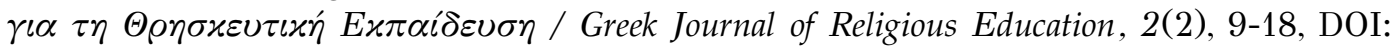
$10.30457 / 031120191$

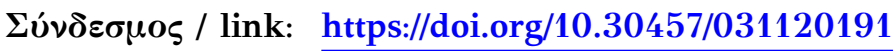

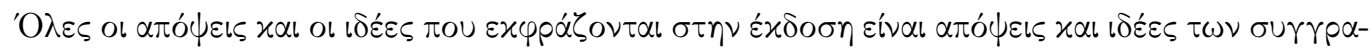

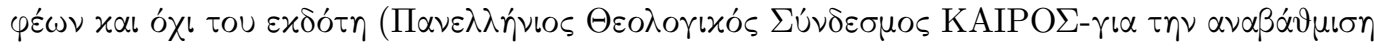

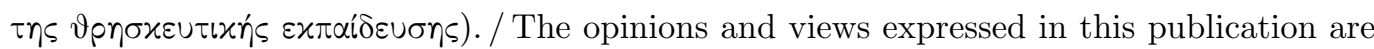
the opinions and views of the authors and not of the publisher (KAIROS - Greek Theological Association for the improvement of the Religious Education).

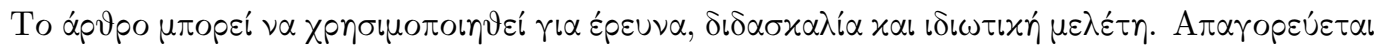

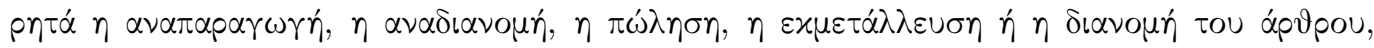

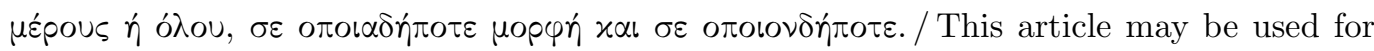
research, teaching, and private study purposes. Any substantial or systematic reproduction, redistribution, reselling, licensing or distribution in any form to anyone is forbidden. 


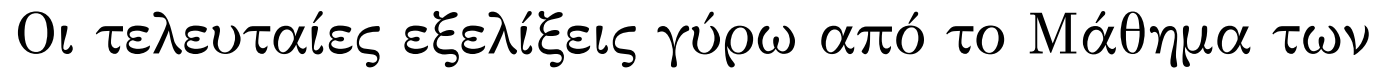

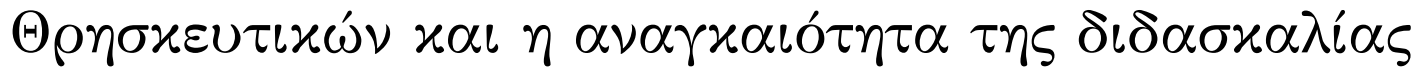

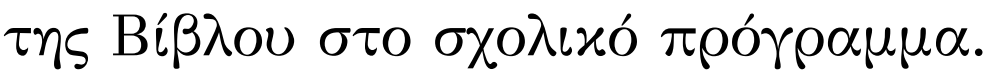

\section{Recent Developments concerning Religious Education and the Necessity of Teaching the Bible in the School Curriculum.}

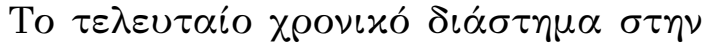
$\mathrm{E} \lambda \lambda \alpha \dot{\alpha} \delta \alpha v \pi \dot{n} \rho \xi \alpha \nu \theta v \varepsilon \lambda \lambda \omega \dot{\delta} \varepsilon \iota \varsigma \varepsilon \xi \varepsilon \lambda i \xi \varepsilon \iota \varsigma$

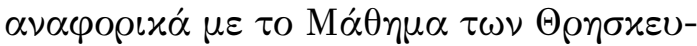

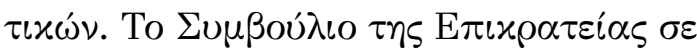

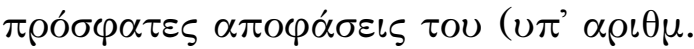

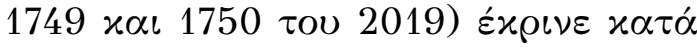
$\pi \lambda \varepsilon \iota$ $\eta \eta \varphi i \alpha \tau \alpha \pi \alpha \rho o ́ v \tau \alpha \pi \rho o \gamma \rho \alpha ́ \mu \mu \alpha \tau \alpha$

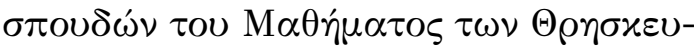

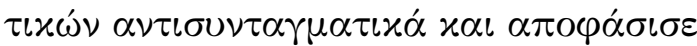

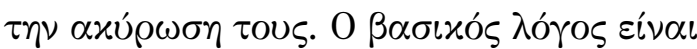

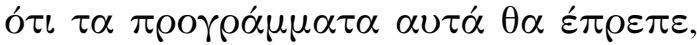

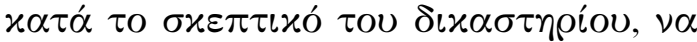

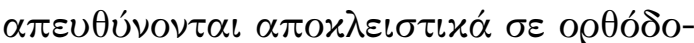

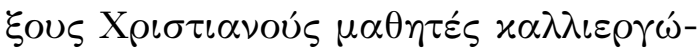

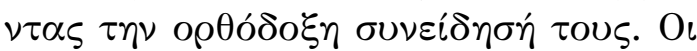

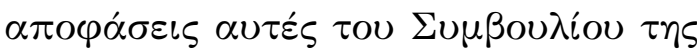

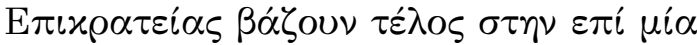

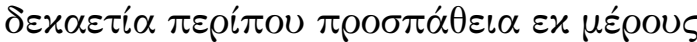

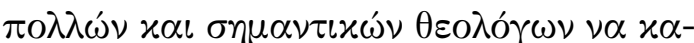

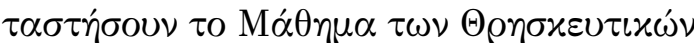

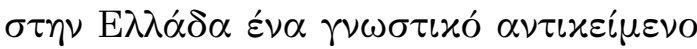

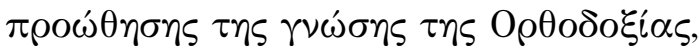

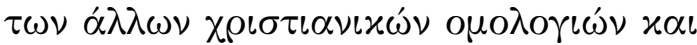

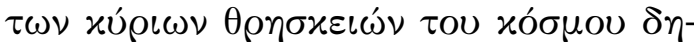

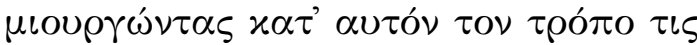

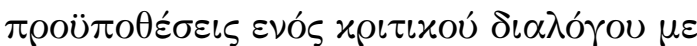

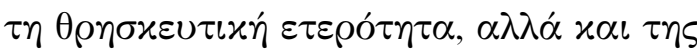

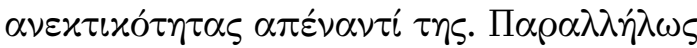

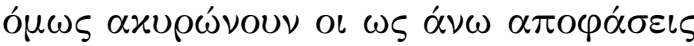

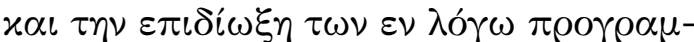

During the last few months, there have been turbulent developments regarding the teaching of religion in Greece. In its recent decisions (Nos. 1749 and 1750 of 2019), the Council of State, namely the Supreme Administrative Court in Greece, overwhelmingly declared as unconstitutional the present curriculum of religion in primary and secondary education and, therefore, ordered its cancellation. The main reason for the Court's verdict is that this curriculum should be aimed exclusively at Orthodox Christian school pupils by cultivating their Orthodox self-conscience. The above decisions of the Council of State have put an end to nearly a decade of efforts by many prominent theologians to open up religion classes in Greece by promoting knowledge of Orthodoxy, other Christian denominations and all world-religions, thus meeting the prerequisites for a genuinely critical dialogue with religious diversity and for promoting tolerance. At the same time, the above decisions also canceled the pursuance of this curriculum to present both Christianity and the religious phenomenon as a whole within the modern-day world by highlighting the importance of religion for 


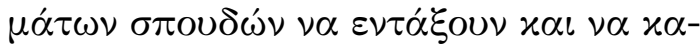

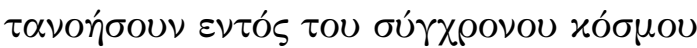

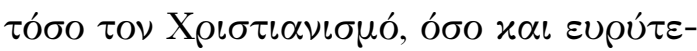

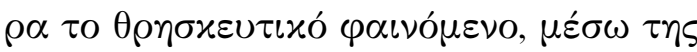

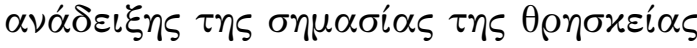

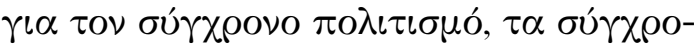

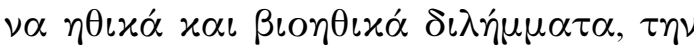

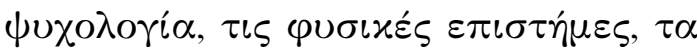

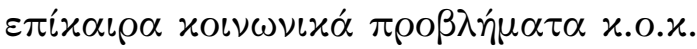

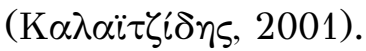

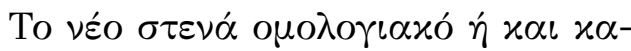

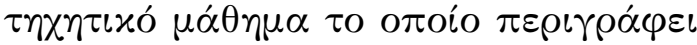

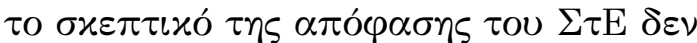

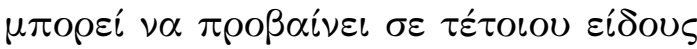
$\alpha \nu o^{\prime} \gamma \mu \alpha \tau \alpha$, ó $\pi \omega \varsigma \tau \alpha \pi \alpha \rho \alpha \pi \alpha \dot{\nu} \omega, \alpha \varphi \circ{ }^{\prime}$, ó $\pi \omega \varsigma \pi \rho \circ \alpha \nu \alpha \varphi \varepsilon ́ \rho \alpha \mu \varepsilon, \alpha \pi \varepsilon v \theta \dot{v} \nu \varepsilon \tau \alpha l \alpha \pi 0^{-}$

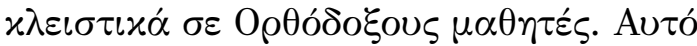

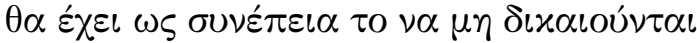

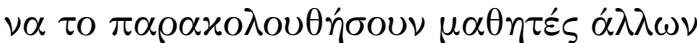

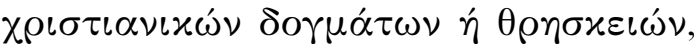

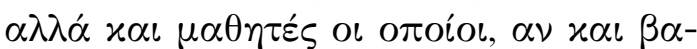

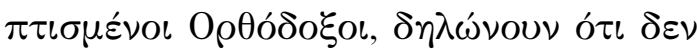

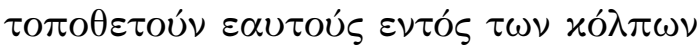

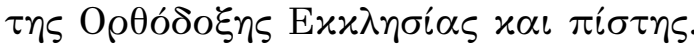

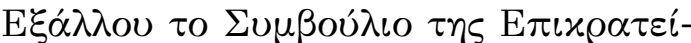

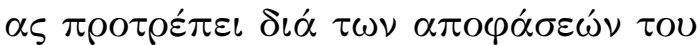

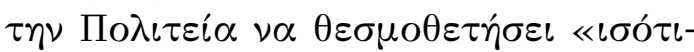

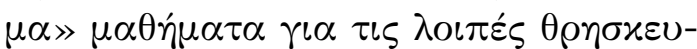

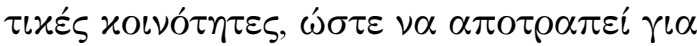

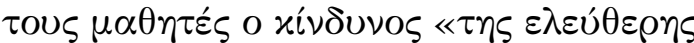

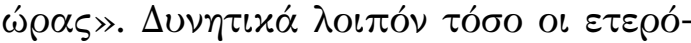

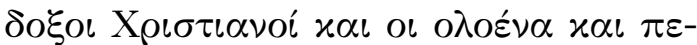

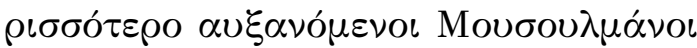

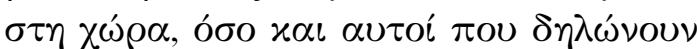
$\alpha \theta \varepsilon \circ \iota \dot{\eta} \theta \rho \eta \sigma x \varepsilon v \tau \iota x \alpha \dot{\alpha} \alpha \delta \iota \alpha \dot{\alpha} \varphi \rho \circ \iota, \theta \alpha \mu \pi 0^{-}$

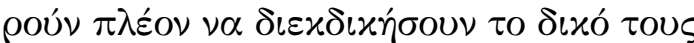

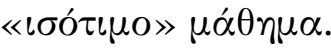

$\mathrm{E} \pi \iota \pi \lambda \varepsilon^{\prime} O \nu \delta \varepsilon, \mu \varepsilon \tau \iota \zeta \alpha \pi O \varphi \alpha ́ \sigma \varepsilon \iota \varsigma \tau O \nu$

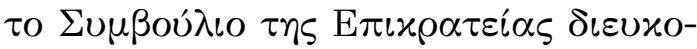

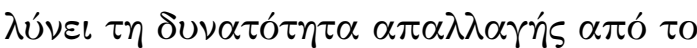

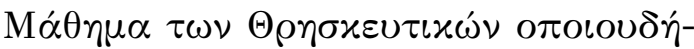

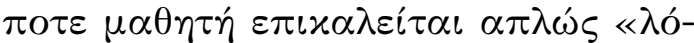

contemporary culture, ethics, bioethical issues, psychology, natural sciences, and current social problems.

According to the Council of State's reasoning, the new confessional or even catechetical religion classes cannot have an open character, since, as already mentioned, they are supposed to be addressed exclusively to OrthodoxChristian pupils. This reality will result in pupils who belong to other Christian denominations or who come from different religious backgrounds altogether, not being allowed to attend OrthodoxChristian religion classes. The above also applies even to those pupils baptized Orthodox who declare that they do not consider themselves as belonging to the Orthodox Church or as adhering to the Orthodox faith. Moreover, through its decisions, the Council of State urges the State to organize equivalent religion classes addressed to other religious communities, so as to avoid free time for pupils during their school attendance. Thus, potentially, non-Orthodox Christians and the everincreasing number of Muslims in the country, as well as those who profess to be atheist or religiously indifferent, will now be able to claim their own equivalent religion classes.

Furthermore, the Council of State facilitates the exemption of any pupil from religion classes merely by an appeal to "reasons of religious conscience", since a more detailed explanation of such reasons 


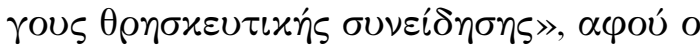

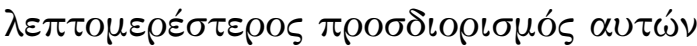

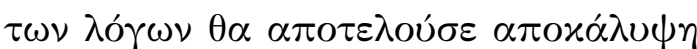

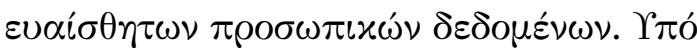

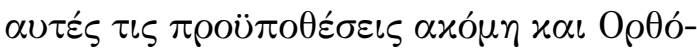
$\delta о \xi o \iota$ X

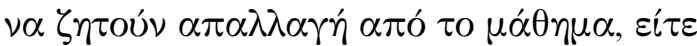

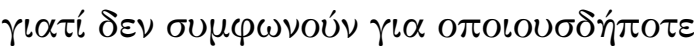

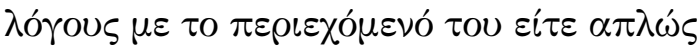

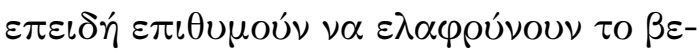

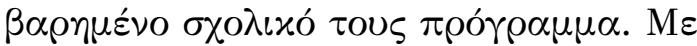

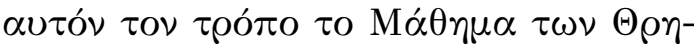

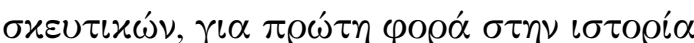

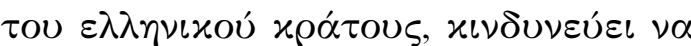

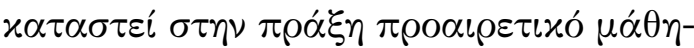

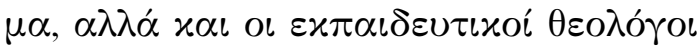

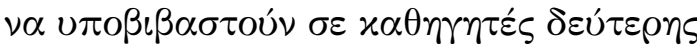

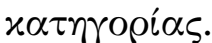

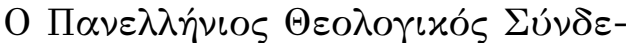

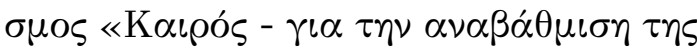
$\theta \rho \eta \sigma x \varepsilon v \tau \iota x \eta \dot{\varsigma} \varsigma \varepsilon x \pi \alpha i \delta \varepsilon v \sigma \eta \eta \varsigma » \sigma \tau \dot{\eta} \rho l \xi \varepsilon \tau \alpha$

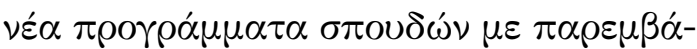

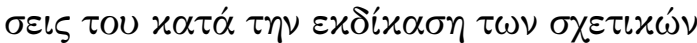

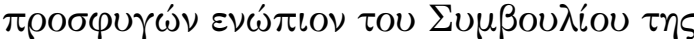

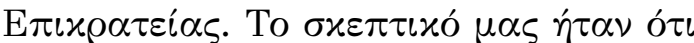

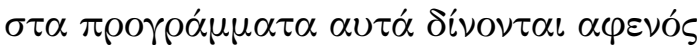

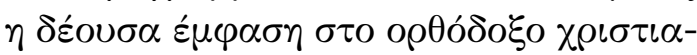

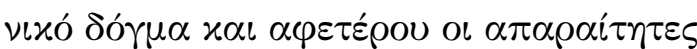

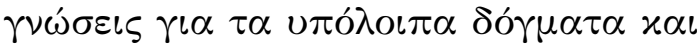

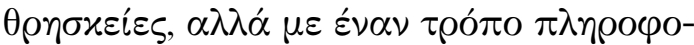

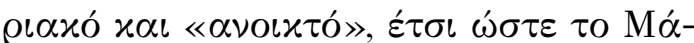
$\theta \eta \mu \alpha \tau \omega \nu \Theta \rho \eta \sigma x \varepsilon v \tau \iota x \omega \dot{\nu} \nu \nu \alpha \alpha \pi \varepsilon v \theta \dot{v} \nu \varepsilon \tau \alpha \iota$

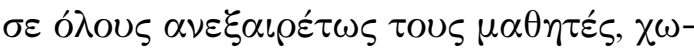

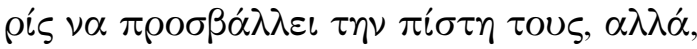

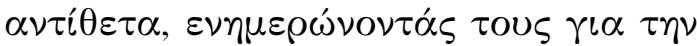

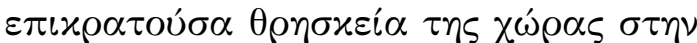

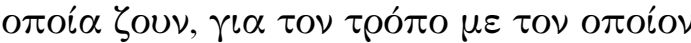

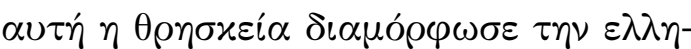

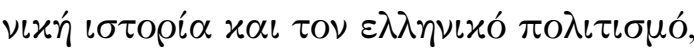

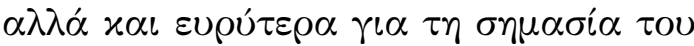

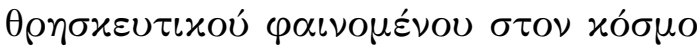

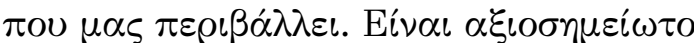
ó $\tau \iota \varepsilon \iota \delta \iota x \eta ́ n ~ \varepsilon \pi \iota \tau \rho O \pi \dot{\eta} \alpha \pi 0 \tau \varepsilon \lambda o u ́ \mu \varepsilon \nu \eta \alpha \pi o ́$

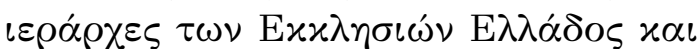

would disclose sensitive personal data. Under these conditions, even OrthodoxChristian pupils will now be able to seek exemption from religion classes, either because they do not agree with their content or simply in order to free their busy schedule from an "unnecessary burden." In this way, for the first time in the history of the Greek State, religion is in danger of becoming an optional school-course, while theologians could be practically relegated to second-class schoolteachers.

"Kairos," the Greek Theological Association for the improvement of Religious Education, supported the last curriculum by intervening in the adjudication of the relevant appeals before the Council of State. Our rationale was that the curriculum in question focuses on the Orthodox Christian teaching and other Christian denominations and worldreligions, and in an informative and "open" manner at that. Thus, regardless of their individual religious beliefs, it enables all pupils to attend religion classes in order to be informed about the dominant religion of the country in which they live, how this religion shaped Greek history and culture, and more broadly about the importance of the religious phenomenon worldwide. It is noteworthy that a select committee consisting of bishops officially representing the Orthodox Churches of Greece and Crete had already long before expressed their assent to the specific curriculum in advance. 


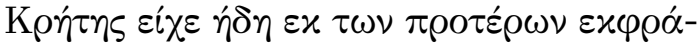

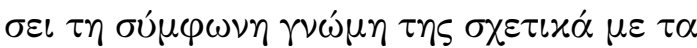

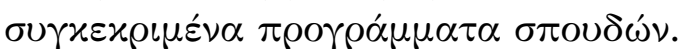

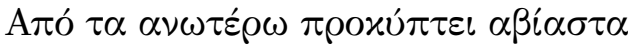

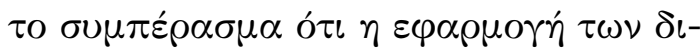

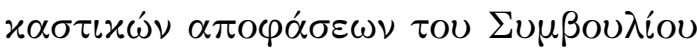

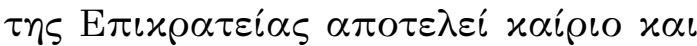

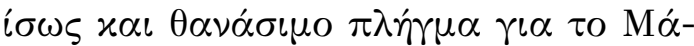

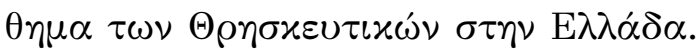

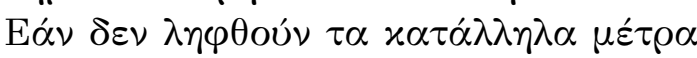

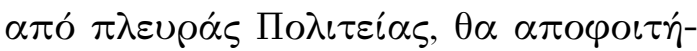

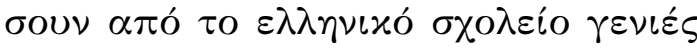

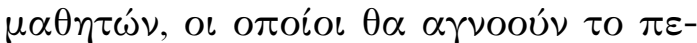

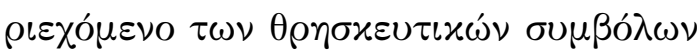

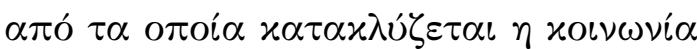

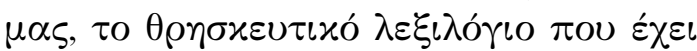

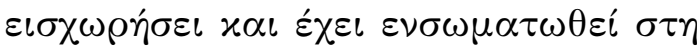

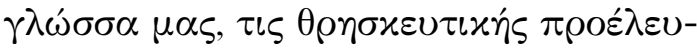

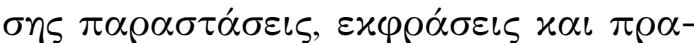

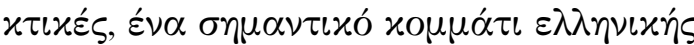

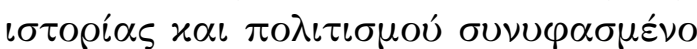

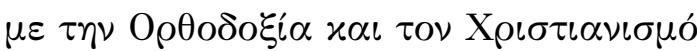

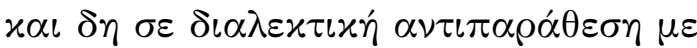

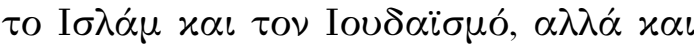

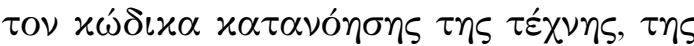

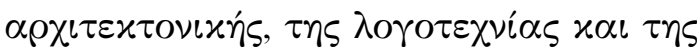

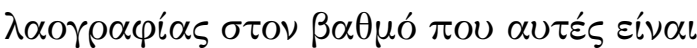

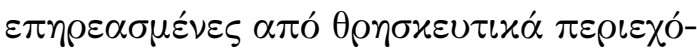
$\mu \varepsilon \nu \alpha x \alpha l_{l} \sigma v \gamma x \varepsilon i \mu \varepsilon v \alpha$.

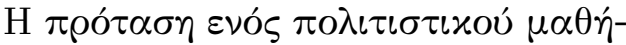

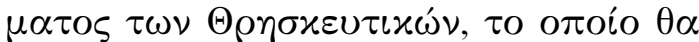

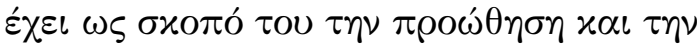

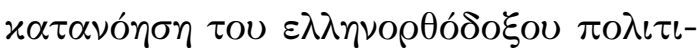

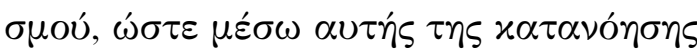
oเ $\mu \alpha \theta \eta \tau \varepsilon \dot{\varepsilon} \nu \alpha \mu \pi 0 \rho \varepsilon ́ \sigma o u \nu \nu \alpha \varepsilon \xi o \iota x \varepsilon \iota \omega-$

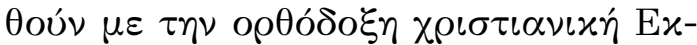

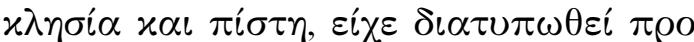
$\pi \circ \lambda \lambda \circ \sigma^{\prime} \gamma \alpha \pi \rho \omega ́ \tau \eta \eta$ 

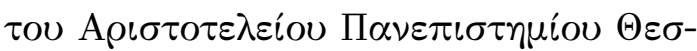

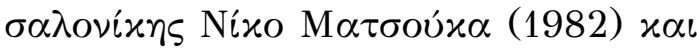

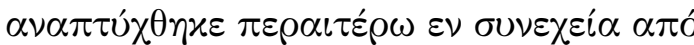

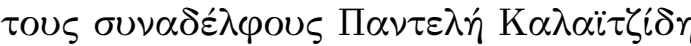

From the above, it is clear that the implementation of the Council of State's verdict can be a crucial and perhaps even a deadly blow to Religious Education in Greece. Unless the Greek State takes appropriate measures, generations of pupils will graduate from the Greek school-system being ignorant of the meaning of commonplace religious symbols, religious vocabulary incorporated into everyday language, as well as the religious origin of stock images, ideas, practices, and customs. Furthermore, they will lack the tools to understand the interrelatedness of Greek history and culture with Orthodox Christianity, to interpret their dialectical relationship with Islam and Judaism, and even to contextualize art, architecture, literature, and folklore to the extent that these are influenced by religious contents.

The suggestion of a religion curriculum that aims to promote and understand Greek Orthodox culture so that students can familiarize themselves with the Orthodox Christian Church and faith had long been formulated for the first time by the late Nikos Matsoukas, a Professor at the School of Theology of the Aristotle University of Thessaloniki. Matsoukas's proposal was further developed by colleagues Pantelis Kalaitzidis and Stavros Yangazoglou. 


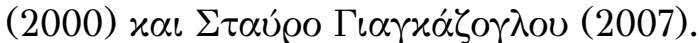

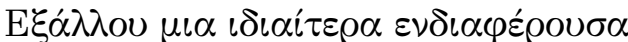

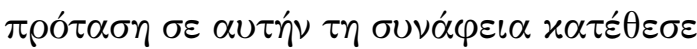

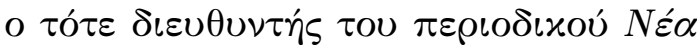

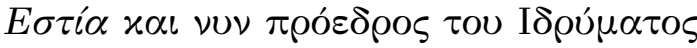

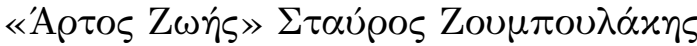
(2006), $\alpha \nu \alpha \varphi \varepsilon \rho o ́ \mu \varepsilon \nu о \varsigma ~ \sigma \varepsilon ~ \varepsilon ́ v \alpha \mu \alpha ́ \theta \eta \mu \alpha$

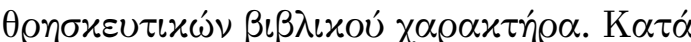

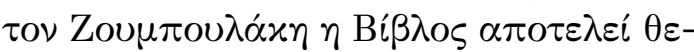

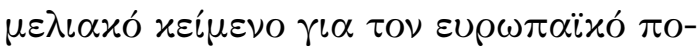

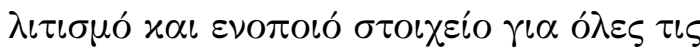

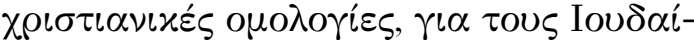

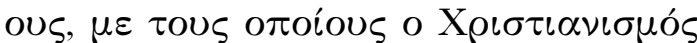

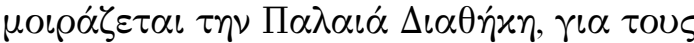

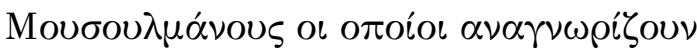

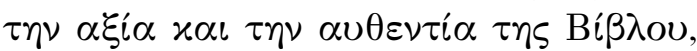

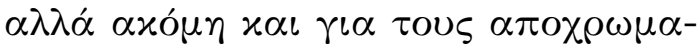

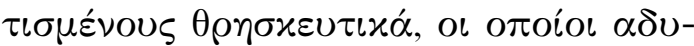

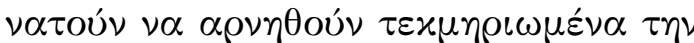

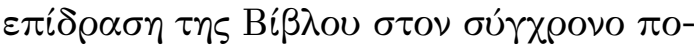

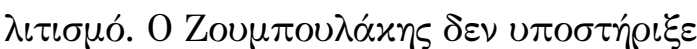

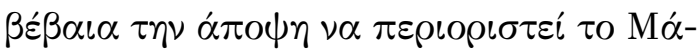
$\theta \eta \mu \alpha \tau \omega \nu$ $\Theta \rho \eta \sigma x \varepsilon v \tau \iota x \omega \dot{\omega} \nu \alpha \pi 0 x \lambda \varepsilon \iota \sigma \tau \iota x \alpha ́$

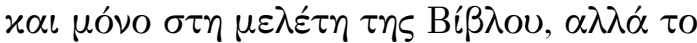

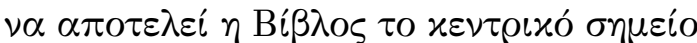

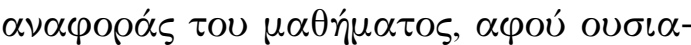

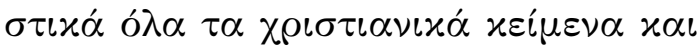

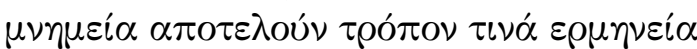

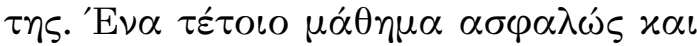

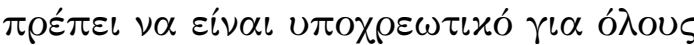

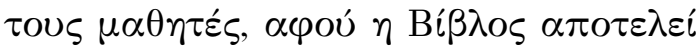

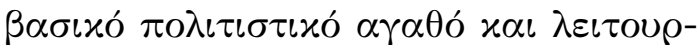

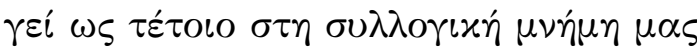

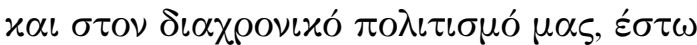

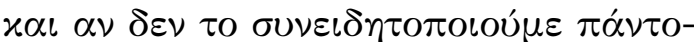

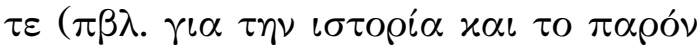

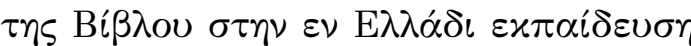

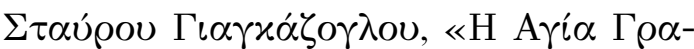

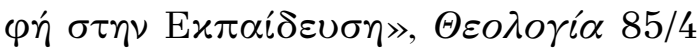
[2014], 211-241).

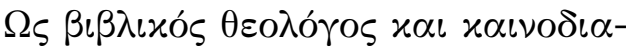

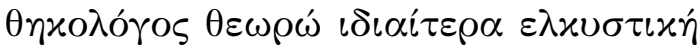

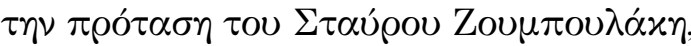

In this context, a particularly compelling proposal was made by Stavros Zoumboulakis, then director of the New Hestia journal and currently president of the Artos Zoes Foundation, referring to a kind of Religious Education of biblical character. The Bible is a foundational text of European civilization and an integral element for all Christian confessions. It is also relevant for both Jews, with whom Christianity shares the Old Testament and Muslims who recognize the Bible's value and authority, and even for those being religiously indifferent, who are unable convincingly to negate the Bible's impact on modern-day culture. Zoumboulakis did not, of course, support the idea of confining Religious Education solely to the study of the Bible, but to bring the Bible into its center, since virtually all Christian texts and monuments are in some way based on its interpretation. Such religion classes should undoubtedly be obligatory for all pupils, since the Bible is a foundational cultural treasure and functions as such within our collective memory and contemporary culture, even if we often fail to realize this fact.

As a biblical theologian and a New Testament scholar, I find Zoumboulakis's proposal particularly appealing, without 


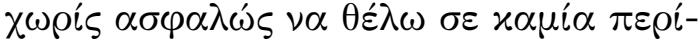

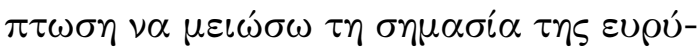

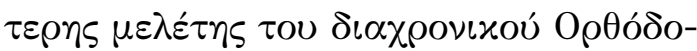

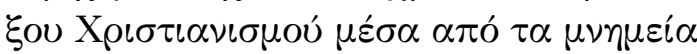

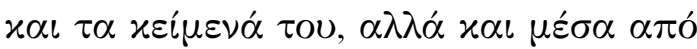

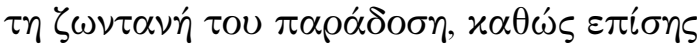

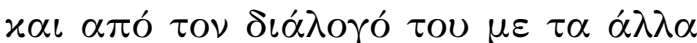

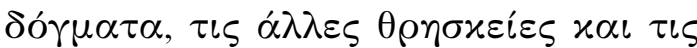
$\varepsilon \pi \iota \tau \tau \dot{\eta} \mu \varepsilon \varsigma$. $\Theta \varepsilon \dot{\varepsilon} \lambda \omega$ ó $\mu \omega \varsigma \varepsilon \delta \dot{\omega} \nu \alpha \varepsilon \xi \dot{\alpha} \rho \omega \tau \eta$

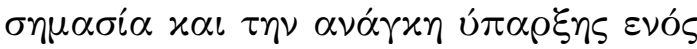

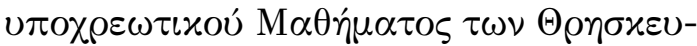

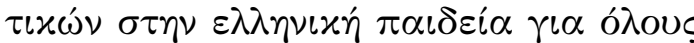

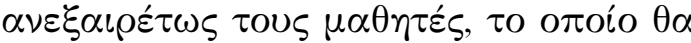

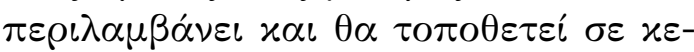

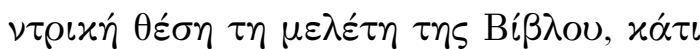

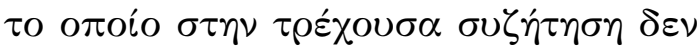

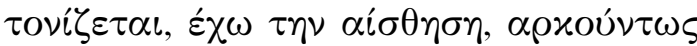

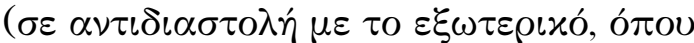
$\delta i v \varepsilon \tau \alpha \iota \iota \delta \iota \alpha i \tau \varepsilon \rho \eta \varepsilon \varepsilon \mu \varphi \alpha \sigma \eta \sigma \tau \eta \delta \imath \delta \alpha x \tau \imath x \dot{\eta}$

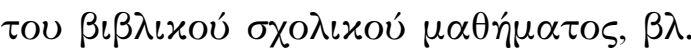
$\varepsilon \nu \delta \varepsilon \iota x \tau \iota x \alpha ́$ (Theißen, 2003; Zimmermann \& Zimmermann, 2013; Roncace \& Gray,

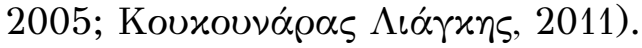

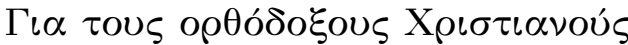

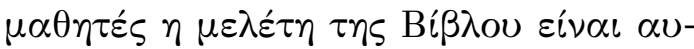

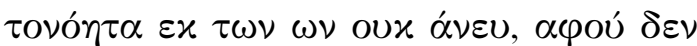

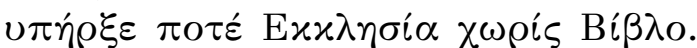

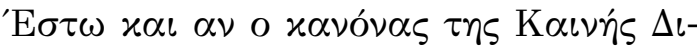

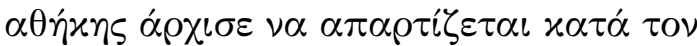

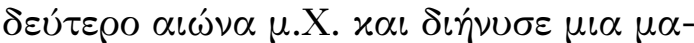

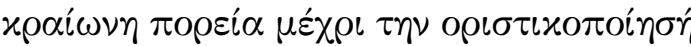

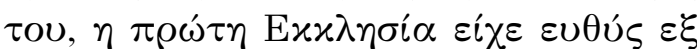

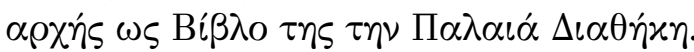

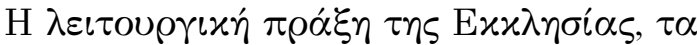

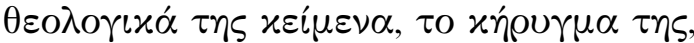

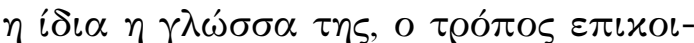

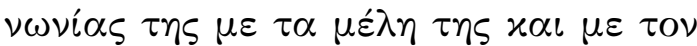

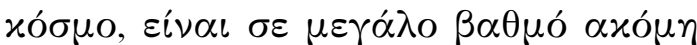

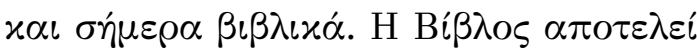

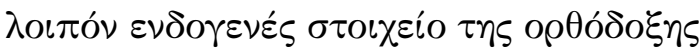

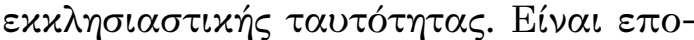

of course wanting to downplay the importance of the study of Orthodox Christianity as a whole through its monuments and texts, its lively tradition, as well as through its dialogue with the other Christian doctrines and religions. Here, however, I would like to emphasize the significance and necessity of having a compulsory religion class in the Greek education-system for all pupils regardless, which will focus on the study of the Bible. I am under the impression that this particular perspective is not being stressed enough, as opposed to the practice in other countries with a Christian background (see, for example, Gerd Theißen, Zur Bibel motivieren: Aufgaben, Inhalte und Methoden einer offenen Bibeldidaktik, Gütersloh, Chr. Kaiser, 2003; Mirjam Zimmermann and Ruben Zimmermann, Handbuch Bibeldidaktik, Tübingen, Mohr Siebeck, 2013 - Mark Roncace and Patrick Gray [eds.], Teaching the Bible: Practical Strategies for Classroom Instruction, Atlanta, Society of Biblical Literature, 2005).

To students who are members of the Orthodox Church, the significance of studying the Bible is self-evident, since there has never been a Church without a Bible. Even though the books of the New Testament started being collected in the second century C.E. and the canon itself went a long way until it was finalized, the early Church used the Old Testament as its Bible from the very beginning. The liturgical practice of the Church, its theological texts, its preaching, its language, its way of communicating with its members and the world are still biblical to a great extent. Thus, the Bible is an intrinsic element of Orthodox Church identity. It is, therefore, particularly worrying that under the new 


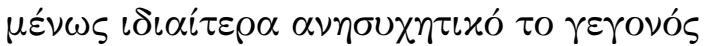

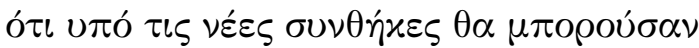

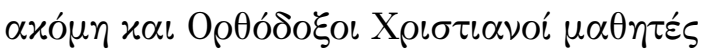

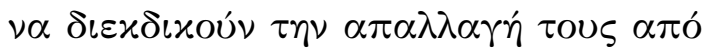
$\tau o \mu \alpha \dot{\theta} \eta \mu \alpha \tau \omega \nu$ $\Theta \rho \eta \sigma x \varepsilon v \tau \iota x \omega \dot{\omega} \nu, \mu \varepsilon \alpha \pi 0^{-}$

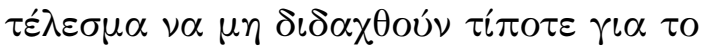

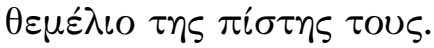

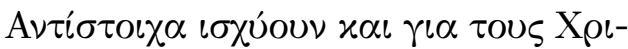

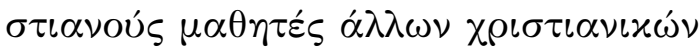

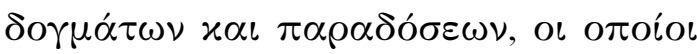

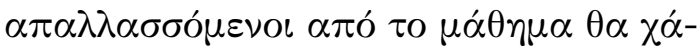

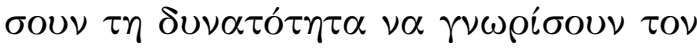

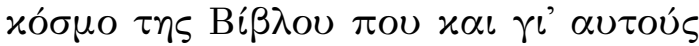

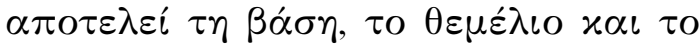

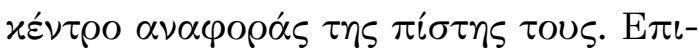

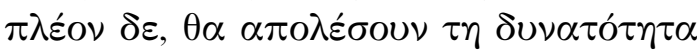

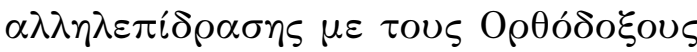

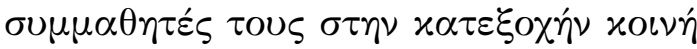

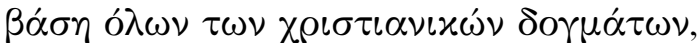

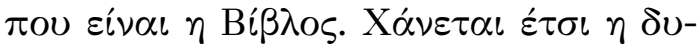

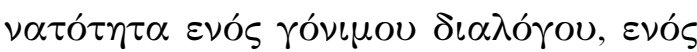
$\pi \lambda \eta{ }^{\prime} \alpha \dot{\alpha} \sigma \mu \alpha \tau \sigma \varsigma, \mu \iota \alpha \varsigma \alpha \lambda \lambda \eta \lambda \lambda o \gamma \nu \omega \rho \iota \mu i \alpha \varsigma$

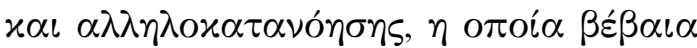

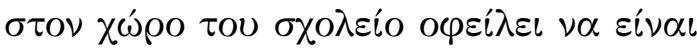

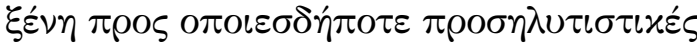
$\varepsilon \pi \iota \delta \iota \omega \xi \varepsilon \iota \varsigma$.

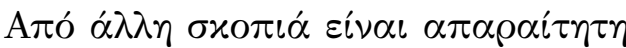

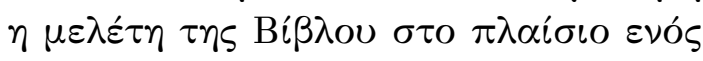

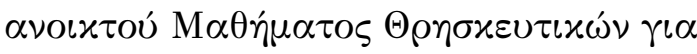

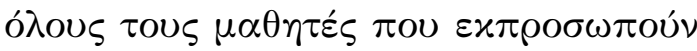

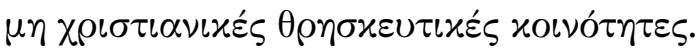

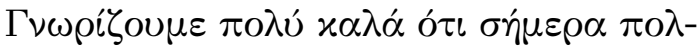

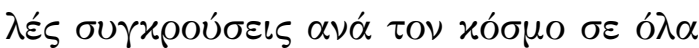

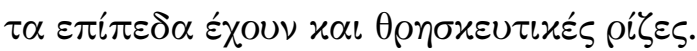

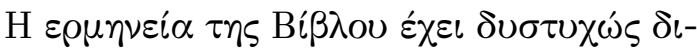

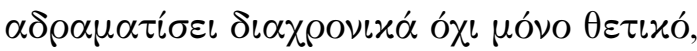

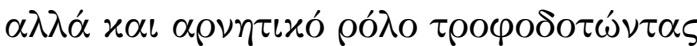

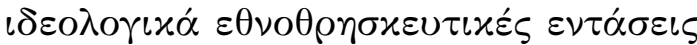

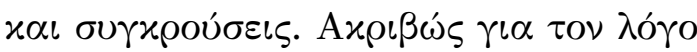

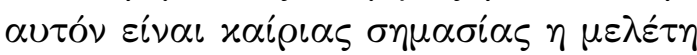

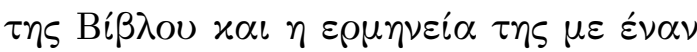

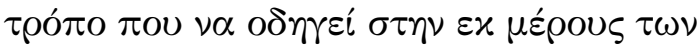

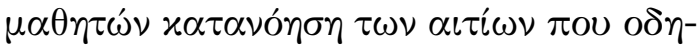

circumstances, even Orthodox Christian students could claim their exemption from religion classes, resulting in their not being taught anything about their faith's foundational text.

The same also applies to nonOrthodox Christian pupils, who, by being exempted from religion classes, will lose the opportunity to become acquainted with the world of the Bible, which for them too is the foundation and the reference center of their faith. Also, they will lose the opportunity to interact with their Orthodox classmates concerning the Bible as the shared basis of all Christian denominations. Thus, the possibility of fruitful dialogue and a mutual approach, familiarization, and understanding will be lost. Needless to say, of course, that in the school environment, any such mutual approach must be entirely devoid of any proselytizing aspirations.

From a different point of view, it is also necessary to offer Bible-study in a context of open religion classes addressed to pupils who represent non-Christian religious communities as well. Nowadays, many conflicts around the world at all levels have religious roots. Unfortunately, the interpretation of the Bible has played not only a positive but also a negative role over time, fueling ideological ethnoreligious tensions and conflicts. Therefore, the interpretation of the Bible to guide pupils to understand the causes which lead, on the one hand, to religious fanaticism and on the other hand, to accepting and practicing the authentic Christian teaching of love towards all 


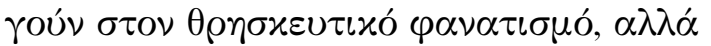

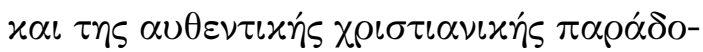

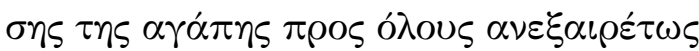

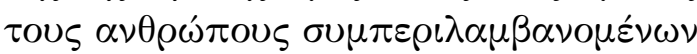

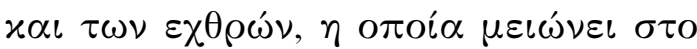

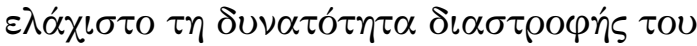

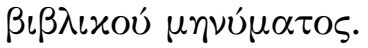

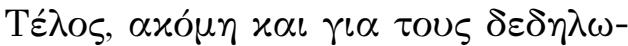

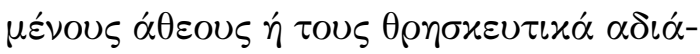

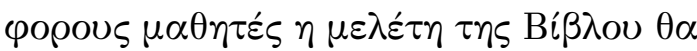

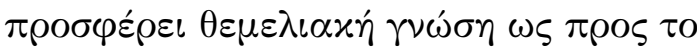

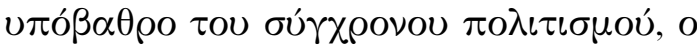

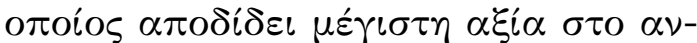
$\theta \rho \omega ́ \pi \iota \nu o r \rho o ́ \sigma \omega \pi o, \sigma \tau \alpha \alpha \nu \theta \rho \omega ́ \pi \iota \nu \alpha \delta \iota-$

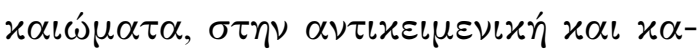

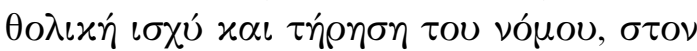

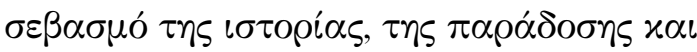

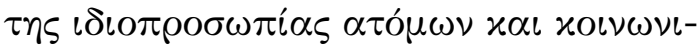

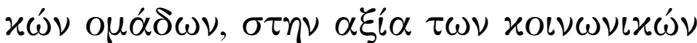

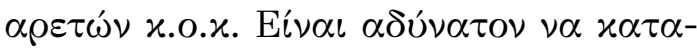

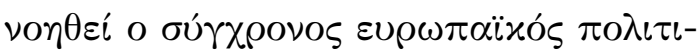

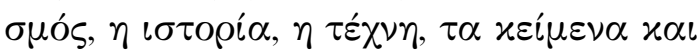

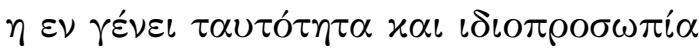

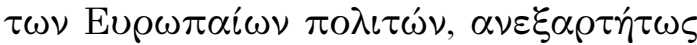

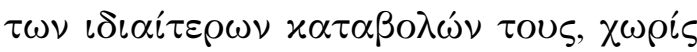

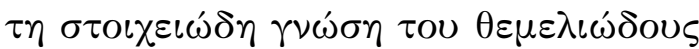

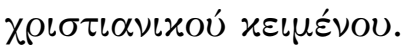

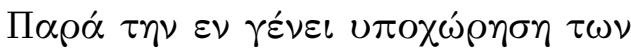

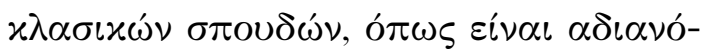

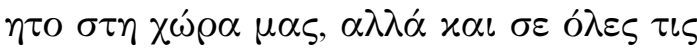

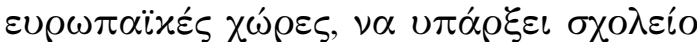

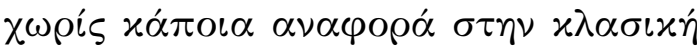

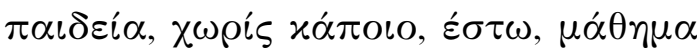

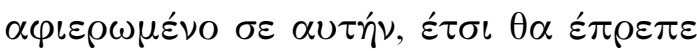

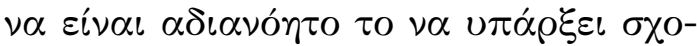

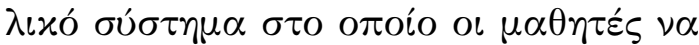

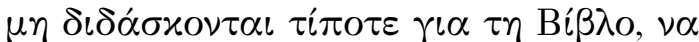

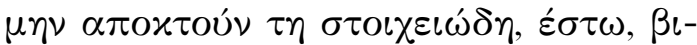

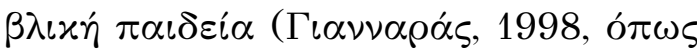

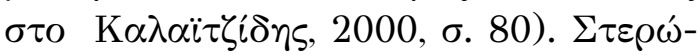

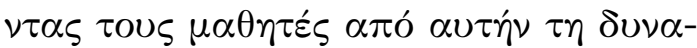

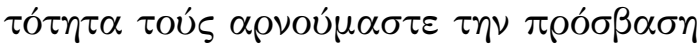

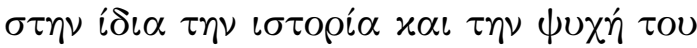

people -enemies included- is of crucial importance. Such an interpretation would minimize the possibility of the biblical message being perverted and misused.

Finally, even for declared atheists or religiously indifferent pupils, the study of the Bible can provide a fundamental insight into the background of modernday civilization that focuses on the individual, human rights, the universal authority and observance of the law; a civilization that respects the history, tradition, and identity of both individuals and social groups, while holding social virtues in high regard. It is impossible to understand contemporary European culture, history, art, texts, as well as the overall identity of modern-day European citizens, regardless of their particular backgrounds, without at least some basic knowledge of the Bible.

Despite the general reduction of classical education, both in Greece and in all other European countries, it would be unthinkable to have a school-system without any reference to it. Accordingly, it should be unimaginable to have a school system in which students would be taught nothing at all about the Bible, a curriculum in which they would not acquire even the most basic biblical education. By depriving students of such an opportunity, we deny them access to the very history and soul of Hellenism, Christianity, and European civilization. It is indicative of the educational value of the Bible in the modern Greek context, that the New Testament, the all-time 


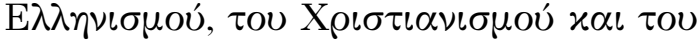

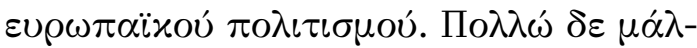

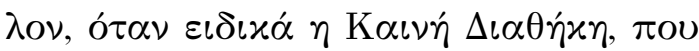

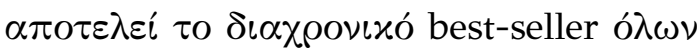

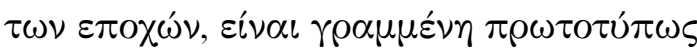

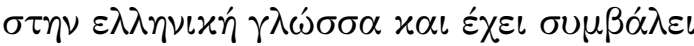

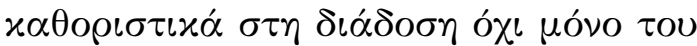

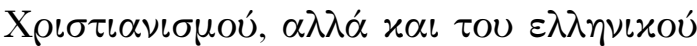

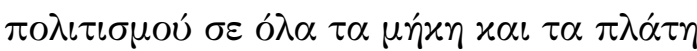

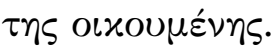

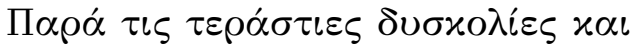

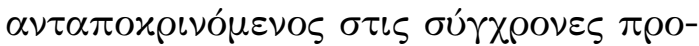

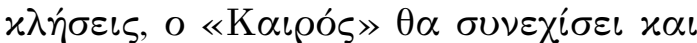

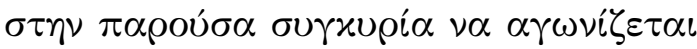

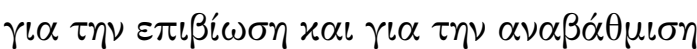

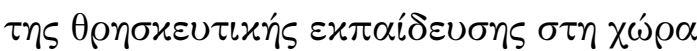

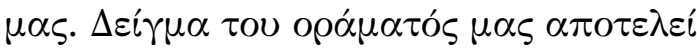

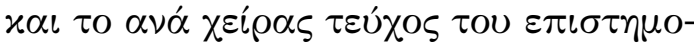

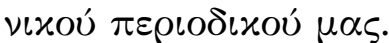

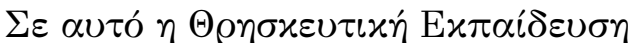

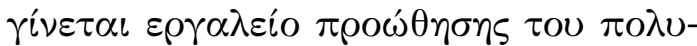

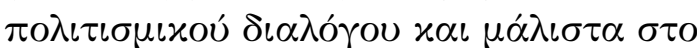
$\varepsilon \lambda \lambda \eta \nu \iota \varkappa o ́ ~ \varepsilon \varkappa \pi \alpha \iota \delta \varepsilon v \tau \iota \varkappa o ́ ~ \sigma u ́ \sigma \tau \eta \mu \alpha$ (A入-

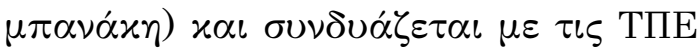

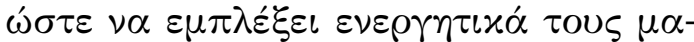

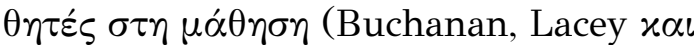

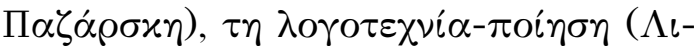

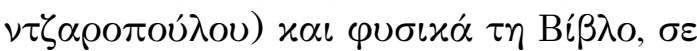

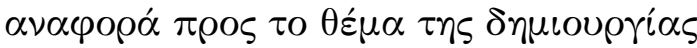

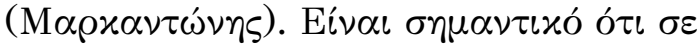

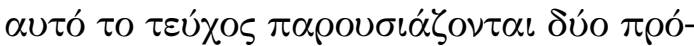

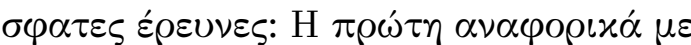

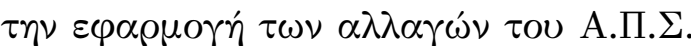

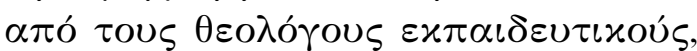

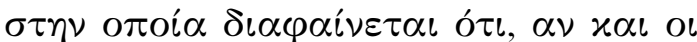

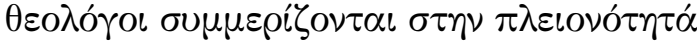

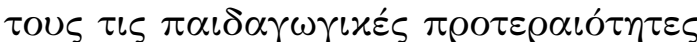
$\tau \omega \nu \alpha \lambda \lambda \alpha \gamma \omega \dot{\nu} \nu \alpha \tau \tau \omega \dot{\nu}, v \pi \alpha \dot{\alpha} \rho \varepsilon l \delta v \sigma x o \lambda i \alpha$

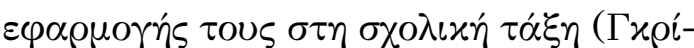

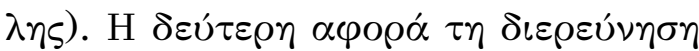

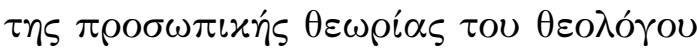

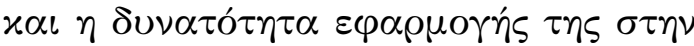

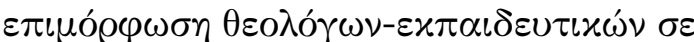

universal best-seller, was initially written in the Greek language and has contributed decisively to the spread not only of Christianity but also of Greek culture and thought in all parts of the world.

Despite the enormous difficulties and need to respond to present-day challenges, our Association will continue to work for the survival and improvement of Religious Education in Greece. A sample of our vision is the new issue of our scholarly journal at hand.

In this, Religious Education becomes a tool for promoting multicultural dialogue even in the Greek educational system (Albanaki) and is combined with ICT to actively engage students in learning (Buchanan, Lacey, and Pazarski), with literature and poetry (Lintzaropoulou), with the Bible to teach the subject of creation (Markadonis). It is important that this issue presents two recent researches in Greece. The first regarding the implementation of the changes to the Curriculum of the RE by the RE teachers, which find that, although most RE teachers share the pedagogical priorities of the changes, there is a difficulty in applying them to the classroom (Grilis). The second concerns the exploration of the RE teachers' personal theory and the possibility of applying a reflective theological-teacher training in the Greek context (Vallianatos). Finally, the issue features the reports of the 3rd General Meeting of KAIROS in Athens 


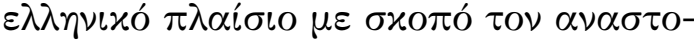

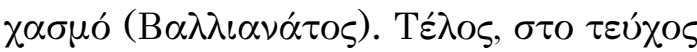

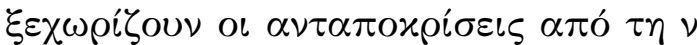

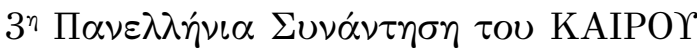

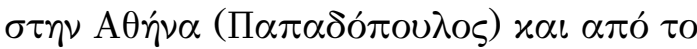

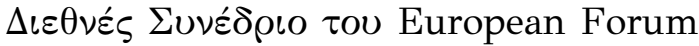
for Teachers of Religious Education $\sigma \tau o$ $\Delta o v \beta \lambda i v o$ (П $\alpha \alpha \sigma x \varepsilon v o ́ \pi о \nu \lambda о \varsigma)$.

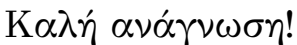

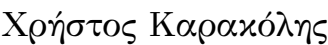

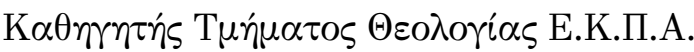

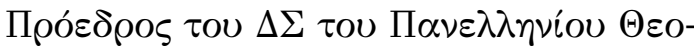

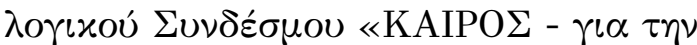

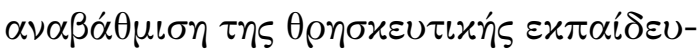
ons».
(Papadopoulos) and the international Conference of the European Forum for Teachers of Religious Education in Dublin (Paraskevopoulos).

Enjoy reading it!

\section{Christos Karakolis \\ Professor \\ Department of Theology}

National and Kapodistrian University of Athens

President of Kairos: Greek Theological Association for the improvement of Religious Education

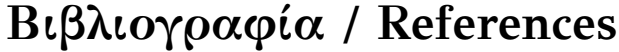

Roncace, M., \& Gray, P. (eds.) (2005). Teaching the Bible: Practical Strategies for Classroom Instruction. Atlanta: Society of Biblical Literature.

Theißen, G. (2003). Zur Bibel motivieren: Aufgaben, Inhalte und Methoden einer offenen Bibeldidaktik. Gütersloh: Chr. Kaiser.

Zimmermann, M., \& Zimmermann, R. (2013). Handbuch Bibeldidaktik. Tübingen: Mohr Siebeck.

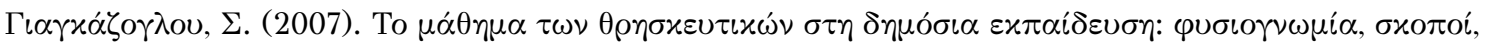

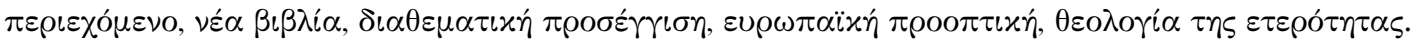

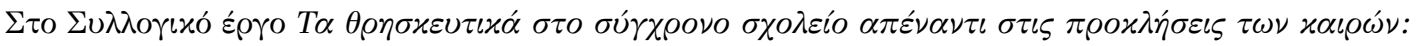

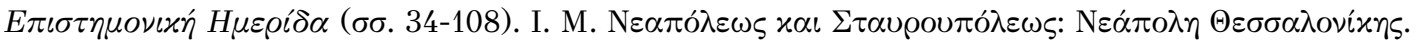

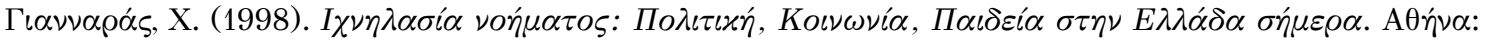
$\Lambda \iota \beta \alpha ́ v \eta$ s.

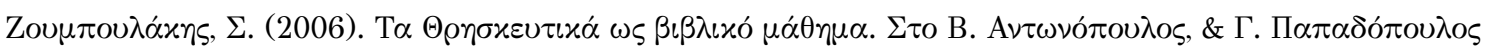

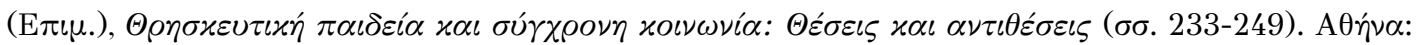
$\mathrm{E} \nu \Pi \lambda \omega$.

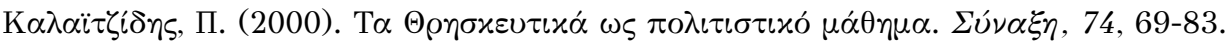

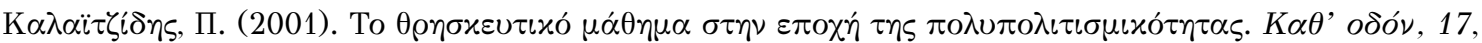
39-50.

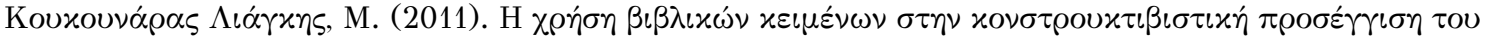

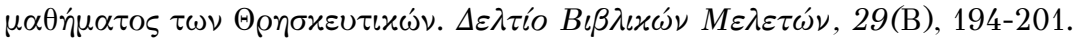

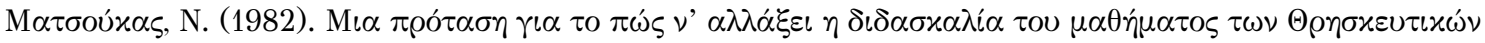
$\sigma \tau \alpha \sigma \chi 0 \lambda \varepsilon i \alpha . \Sigma \dot{\nu} \alpha \xi \eta, 1,35-41$. 